\title{
Prevalence of stress in junior doctors during their internship training: a cross-sectional study of three Saudi medical colleges' hospitals
}

This article was published in the following Dove Press journal:

Neuropsychiatric Disease and Treatment

25 September 2014

Number of times this article has been viewed

Hamza Mohammad Abdulghani' Mohammad Irshad' Mohammed A Al Zunitan ${ }^{1,2}$ Ali A Al Sulihem ${ }^{1,2}$

Muhammed A Al Dehaim ${ }^{1,2}$

Waleed A Al Esefir ${ }^{1,2}$

Abdulaziz M Al Rabiah',2

Rashid N Kameshki ${ }^{1,2}$

Nourah Abdullah Alrowais ${ }^{2}$

Abdulaziz Sebiany ${ }^{3}$

Shafiul Haque'

'Department of Medical Education, College of Medicine, King Saud University, Riyadh, Saudi Arabia; ${ }^{2}$ Department of Family and

Community Medicine, King Saud University, Riyadh, Saudi Arabia; ${ }^{3}$ Department of Family and Community Medicine, University of Dammam, Dammam, Saudi Arabia

\section{Video abstract}

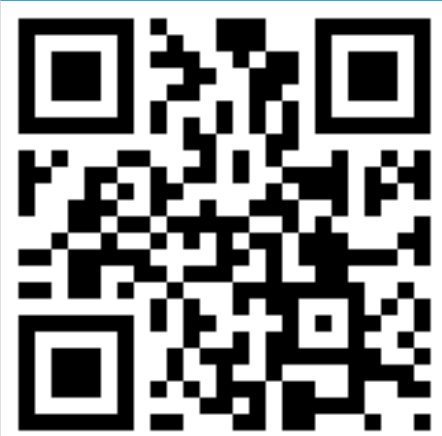

Point your SmartPhone at the code above. If you have a OR code reader the video abstract will appear. Or use: http://dvpr.es/WXgLOT

Correspondence: Hamza Mohammad Abdulghani

Department of Medical Education, College of Medicine, King Saud University, PO Box 230155, Riyadh II321, Saudi Arabia

Tel +966 || $4699 \mid 77$

Fax +966 II 467 I967

Email hamzaabg@gmail.com
Background: Medical science is perceived as a stressful educational career, and medical students experience monstrous stress during their undergraduate studies, internship, and residency training, which affects their cognitive function, practical life, and patient care. In the present study, an assessment of the prevalence of self-perceived stress among new medical graduates during their internship training has been performed, and correlations of self-perceived stress with sex, marital status, and clinical rotations have been evaluated.

Patients and methods: Interns of the King Khalid, King Abdulaziz, and King Fahd University hospitals in Saudi Arabia were invited to complete a stress inventory known as the Kessler 10, which is used for stress measurement. Apart from stress evaluation, the questionnaire collected personal data, such as age, sex, and marital status, in addition to information relevant to hospital training, assigned duties, and clinical training rotations.

Results: Our results showed that nearly $73.0 \%$ of interns were under stressed conditions. Most of the interns were affected by a severe level of stress (34.9\%), followed by mild (19.3\%) and moderate $(18.8 \%)$ levels of stress. The stress level was significantly higher $(84.0 \%)$ among female interns in comparison with male interns $(66.5 \%$ ) (odds ratio $=2.64$; confidence interval $=1.59-4.39 ; P<0.0002)$. There were statistically significant differences between the percentages of male and female interns $(P \leq 0.047)$ at mild, moderate, and severe stress levels. Marital status had no role in causing stress. The highest stress level was reported by interns during the clinical rotations of medicine $(78.8 \%)$, followed by surgery $(74.7 \%)$, pediatrics $(72.4 \%)$, obstetrics and gynecology (70.1\%), and emergency (58.3\%). The prevalence of stress among the interns and their corresponding clinical rotations in all three hospitals had significant linear correlations ( $r \geq 0.829, P \leq 0.041)$.

Conclusion: We found a significantly high level of stress among the medical interns. High stress may have negative effects on cognitive functioning, learning, and patient care. Hence, medical interns need support and subsequent interventions to cope with stress.

Keywords: medical education, clinical rotation, medicine, surgery, pediatrics

\section{Introduction}

Internship refers to the 1-year compulsory supervised hospital training required to obtain Bachelor of Medicine and Bachelor of Surgery degrees in Saudi Arabia. It begins just after the completion of medical school, and it is a year of tremendous changes. The internship is a kind of experiential learning during which recent graduates take the opportunity to apply acquired knowledge and skills from their medical school training to real-world situations, and it provides an opportunity for medical graduates to integrate and consolidate their thinking and actions. ${ }^{1-3}$ Also, it bridges the gap between the medical school and being board eligible for medical specialty 
training. ${ }^{4}$ The overall goal of medical education is to produce knowledgeable, competent, and professional physicians who are equipped to care for the nations' sick community, provide advancements in medical science education and research, and most importantly, promote public health care. ${ }^{5}$ The major tasks assigned to medical interns are to provide patient care, register new admissions, and prepare medical records. ${ }^{6}$ Newly graduated physicians who undertake an internship appreciate that the internship is the most stressful period in the life of a medical doctor. ${ }^{7}$

Stress is a subjective phenomenon that results from an event that produces physical or psychological pain. ${ }^{8}$ Stress is a normal part of everyday life; it may either be healthy or unhealthy. For example, feeling a small amount of stress until a solution is reached is known as healthy or positive stress. ${ }^{9}$ Healthy stress is beneficial as a coping strategy to keep awareness, balance, and connection. ${ }^{10}$ Also, it can help to produce desirable effects such as tolerance of ambiguity, self-confidence, and maturity, and it may stimulate the acquisition of knowledge and skills. ${ }^{11,12}$ However, unhealthy or negative stress, which is referred to as excessive stress, can interfere with efficient learning, impair memory, increase anxiety, decrease sleep, cause eating habit-related problems, lead to accident proneness, and decrease problem-solving abilities..$^{13,14}$ Good personal coping skills can counter the effect of stress to a certain extent, so that the strain can be alleviated. ${ }^{15}$ Many studies have assessed the effect of a stressful life of a person on the outcomes of his career, especially in the medical field. ${ }^{16-19}$ Earlier reports suggested that the prevalence of stress among interns ranges from $11 \%-40 \%{ }^{18,19}$ The most negative impact on the residents' emotions occurs repeatedly in the middle of the internship year. ${ }^{20,21}$ Most of the publications unanimously reported that female interns are more severely affected with stress than male interns. , $^{6,21,22}$ However, contradictory associations were reported locally and internationally between marital status and the prevalence of stress. ${ }^{19,21,23}$

Many studies have investigated stress levels among undergraduate students ${ }^{24,25}$ and postgraduates residents. ${ }^{26}$ However, minor attempts have been made to study the stress levels and pertinent causative factors among newly graduated physicians. In the present study, attempts have been made to investigate the prevalence of stress and its severity among physician interns of three Saudi university-based medical hospitals from three major regions (Riyadh, Dammam, and Jeddah) of Saudi Arabia. Also, attempts have been made to evaluate the possible correlations between the level of stress and possible stress-causing factors associated with sex, marital status, and stressful clinical rotations.

\section{Participants and methods}

During the training period of medical interns, the medical colleges of all Saudi universities assign internship training in five mandatory clinical rotations (ie, medicine, surgery, pediatrics, emergency, obstetrics, and gynecology (Ob/Gyn), and one elective specialty [out of several available options]).

\section{Study population}

Newly graduated male and female physicians who were about to complete their internship clinical rotation during the 2012-2013 academic year at the hospitals of three selected medical colleges of universities of the Saudi Kingdom (ie, King Khalid University Hospital [KKUH], King Saud University, Riyadh, Saudi Arabia; King Abdulaziz University Hospital [KAUH], King Abdulaziz University, Jeddah, Saudi Arabia; and King Fahd Hospital of the University [KFHU], University of Dammam, Dammam, Saudi Arabia) were invited to participate in this study.

\section{Data collection methods}

An anonymous, self-administered questionnaire and bilingual (Arabic and English) Kessler 10 Psychological Distress (K10) instrument was employed to measure stress levels. ${ }^{27}$ Questionnaires were distributed to a total of 550 participating interns and collected during different clinical rotations. All participating interns were informed of the objectives of the present study and given an explanation of the instrument. A nonrandom, convenient sampling technique was employed to collect the data due to the varied distribution of interns in three different hospitals and across specialties. All possible efforts were taken to cover all medical specialties in this study. All interns were allowed to respond at their convenience and available times, and their privacy was secured. Most importantly, participation was entirely voluntary.

The K10 instrument has been widely used in populationbased epidemiological studies to measure current (1 month) distress, and is available in several languages including Arabic. ${ }^{25}$ The K10 works without any substantial bias with respect to sex and educational level. The instrument has been designed to measure the severity and level of distress associated with psychological symptoms in population surveys. The K10 questionnaire consists of ten questions in the form of "how often in the past month did you feel ..." and offers specific symptoms such as "tired out for no good reason", "nervous", and "sad or depressed". The five possible 
responses to each question range from "none of the time" to "all of the time" and are scored from 1-5, respectively. The scores for all questions are summed to obtain a total score. The total scores are interpreted as follows: a score $<20$ is considered to represent no stress of any level; a score of 20-24 represents mild stress; a score of 25-29 represents moderate stress; and a score of 30-50 represents severe stress. Also, the questionnaire used in this study included some additional questions related to participants' sex, age, and marital status; the starting date of internship; clinical rotations; and the name of the hospital. The K10 questionnaire had good psychometric properties with a Cronbach's alpha of 0.89 (95\% confidence interval $[\mathrm{CI}]=0.88-0.90)$.

\section{Statistical analysis}

Numerical data were entered in Microsoft Excel and analyzed using SPSS ${ }^{\circledR}$ Statistics, version 19.0 (IBM Corporation, Armonk, NY, USA). The prevalence of an outcome variable along with 95\% CIs were calculated. Pearson's chi-square test and odds ratios (ORs) were used to evaluate and quantify the associations between a categorical outcome and the variables under consideration. The statistical significance level was maintained as $P<0.05$ during the entire analysis.

\section{Ethical considerations}

The present study was approved by the research ethical committees (ie, institutional review boards) of the respective medicine colleges of King Saud University (KSU; Riyadh, Saudi Arabia), King Abdulaziz University (KAU; Jeddah, Saudi Arabia), and University of Dammam.

\section{Results}

A total of 404 interns (out of 550) of the three different university hospitals of the Saudi Kingdom who completed the K10 questionnaire were finally included in the present study, with a response rate of $74 \%$. Among the studied population, $61.9 \%$ (number $[\mathrm{n}]=250$ ) of interns were from $\mathrm{KKUH}$, $20.0 \%(n=81)$ were from KAUH, and $18.1 \%(n=73)$ were from KFHU. The percentage of male participants was nearly double $(62.9 \% ; n=254)$ that of female participants $(37.1 \%$; $\mathrm{n}=150$ ). The participants' demographic data are presented in Table 1. The percentage of married interns was quite low $(19.6 \% ; n=79)$ compared to that of unmarried interns $(80.4 \%$; $\mathrm{n}=325)$. The highest number of participating interns was in the clinical rotation of medicine $(25.7 \% ; n=104)$, followed by surgery $(20.5 \% ; n=83), \mathrm{Ob} / \mathrm{Gyn}(19.1 \% ; \mathrm{n}=77)$, pediatrics $(18.8 \% ; n=76)$, elective clinics $(9.9 \% ; n=40)$, and emergency $(5.9 \% ; n=24)$.
Table I Characteristics of surveyed medical interns

\begin{tabular}{ll}
\hline Participants & $\mathbf{n}(\%)$ \\
\hline Sex & \\
Males & $254(62.9)$ \\
Females & $150(37.1)$ \\
Hospital & \\
KKUH & $250(61.9)$ \\
KAUH & $81(20.0)$ \\
KFHU & $73(18.1)$ \\
Marital status & \\
Married & $79(19.6)$ \\
Unmarried & $325(80.4)$ \\
Clinic & \\
Medicine & $104(25.7)$ \\
Surgery & $83(20.5)$ \\
Ob/Gyn & $77(19.1)$ \\
Pediatrics & $76(18.8)$ \\
Elective subject & $40(9.9)$ \\
Emergency & $24(5.9)$ \\
Stress level & \\
None & $109(27.0)$ \\
Mild & $78(19.3)$ \\
Moderate & $76(18.8)$ \\
Severe & $141(34.9)$ \\
Total & $404(100)$ \\
\hline Abbreviations: $n$, number; KKUH, King Khalid University Hospital; KAUH, King \\
Abdulaziz University Hospital; KFHU, King Fahd Hospital of the University; Ob/Gyn, \\
obstetrics and gynecology. &
\end{tabular}

Surprisingly, the prevalence of stress among the interns was high $(73.0 \% ; n=295)$. This comprised mild $(19.3 \%$; $\mathrm{n}=78)$, moderate $(18.8 \% ; \mathrm{n}=76)$ and severe $(34.9 \% ; \mathrm{n}=141)$ stress levels (Table 1). The interns of KKUH were under severe stress $(31.6 \%)$. In KKUH, the prevalence of severe stress was higher $(58.2 \% ; \mathrm{n}=46)$ among male interns than female interns $(41.8 \% ; \mathrm{n}=33)$, whereas in KFHU, comparable levels of severe stress were found among the male $(51.7 \%$; $\mathrm{n}=15)$ and female $(48.3 \% ; \mathrm{n}=14)$ interns. In contrast, the prevalence of severe stress was higher $(50.6 \%$; $=20)$ among female interns of KAUH compared to the male interns $(39.4 \% ; n=13)$. However, severe stress was slightly higher (by $9.1 \%$ ) among the interns of KAUH compared to those of KKUH. Likewise, a higher (by $8.1 \%$ ) prevalence of severe stress was found among the interns of KFHU compared to that of the interns of KKUH.

Interestingly, the stress levels among married interns (74.7\%) and unmarried interns (72.6\%) were comparable, and the difference was statistically insignificant $(\mathrm{OR}=0.89$; $\mathrm{CI}=0.51-1.57 ; P=0.71)$. With regard to the role or effect of sex on the stress level, most of the male interns were affected by mild stress $(\mathrm{OR}=0.64 ; \mathrm{CI}=0.32-1.23 ; P=0.173)$, whereas female interns were either affected with severe $(\mathrm{OR}=3.21$; $\mathrm{CI}=1.83-5.61 ; P<0.0001)$ or moderate $(\mathrm{OR}=3.02$; 
$\mathrm{CI}=1.59-5.72 ; P=0.0007)$ stress (Table 2). A statistically significant difference was observed between the stress levels of female and male interns ( $\mathrm{OR}=2.64$; $\mathrm{CI}=1.59-4.39$; $P=0.0002)$. The overall stress level was found to be higher among female interns $(84.0 \%)$ compared to male interns (66.5\%). The female interns of KKUH had a high OR of stress $(\mathrm{OR}=2.88 ; \mathrm{CI}=1.44-5.74 ; P=0.003)$ followed by those of KAUH $(\mathrm{OR}=3.25 ; \mathrm{CI}=1.03-10.21 ; P=0.044)$ and KFHU (OR $=1.52$; CI $=0.51-4.48 ; P=0.453$ ). We further studied the linear correlations among the variables using Pearson's correlation $(r)$ tests. The prevalence of mild, moderate, and severe stress levels showed no significant linear correlations between the male and female interns of KKUH ( $r=0.558, P=0.059)$, KAUH $(r=-0.058, P=0.942)$, and KFHU $(r=0.530, P=0.470)$. However, significant linear correlations were found among the female interns of KKUH, $\mathrm{KFHU}$, and KAUH for the prevalence of mild, moderate, and severe stress levels $(r \geq 0.856, P \leq 0.047)$.

The prevalence of stress among the interns of KKUH, KAUH, and KFHU was $70.80 \%(n=177), 77.8 \%(n=63)$, and $75.3 \%(n=55)$, respectively. In comparison with the stress prevalence among interns of $\mathrm{KKUH}$, the interns of KAUH had a higher prevalence of stress $(\mathrm{OR}=1.44 ; \mathrm{CI}=0.80-2.60$; $P=0.223$ ) followed by the prevalence of stress among interns of KFHU (OR $=1.26$; $\mathrm{CI}=0.69-2.29 ; P=0.448)$.

The prevalence of stress among the interns of all the three medical colleges in various clinical rotations was quite varied (Table 3 ). The level of stress was highest in the clinical rotation of medicine $(78.8 \% ; \mathrm{n}=82)$ followed by surgery (74.7\%; $\mathrm{n}=62)$, pediatrics $(72.4 \% ; \mathrm{n}=55), \mathrm{Ob} / \mathrm{Gyn}(70.1 \%$; $\mathrm{n}=54)$, elective clinics $(70.0 \% ; \mathrm{n}=28)$, and emergency clinics
$(58.3 \% ; \mathrm{n}=14)$. The OR of stress among the interns was highest in medicine ( $\mathrm{OR}=2.66 ; \mathrm{CI}=1.04-6.80)$, followed by surgery $(\mathrm{OR}=2.11$; $\mathrm{CI}=0.81-5.45)$, pediatrics $(\mathrm{OR}=1.87$; $\mathrm{CI}=0.72-4.85), \mathrm{Ob} / \mathrm{Gyn}(\mathrm{OR}=1.68 ; \mathrm{CI}=0.65-4.32)$, and elective clinics ( $\mathrm{OR}=1.67$; $\mathrm{CI}=0.58-4.79)$. The emergency clinical rotation was considered the reference category. Interestingly, stress levels among the interns and their corresponding clinics in all three hospitals were found to be significantly linearly correlated $(r \geq 0.829 ; P \leq 0.041)$. The prevalence of moderate stress was highest in the medicine clinic (27.6\%), followed by pediatrics $(25.0 \%), \mathrm{Ob} / \mathrm{Gyn}(19.7 \%)$, surgery (14.5\%), and emergency (5.3\%). Similarly, the prevalence of severe stress followed the order of medicine (29.8\%), Ob/Gyn $(19.9 \%)$, pediatrics $(17.0 \%)$, surgery $(16.3 \%)$, and emergency (5.7\%). In KKUH, the prevalence of severe stress in the medicine, surgery, $\mathrm{Ob} / \mathrm{Gyn}$, pediatrics, emergency, and elective clinics was $41.6 \%(n=9), 44.7 \%(n=17), 44.1 \%(n=15)$, $41.2 \%(n=14), 44.4 \%(n=4)$, and $56.3 \%(n=9)$, respectively. Similarly, the prevalence of severe stress in the medicine, surgery, $\mathrm{Ob} / \mathrm{Gyn}$, pediatrics, emergency, and elective clinics of KFHU was $43.8 \%(n=7), 50.0 \%(n=6), 54.5 \%(n=6), 42.9 \%$ $(n=6), 33.3 \%(n=1)$, and $57.0 \%(n=4)$, respectively. However, in $\mathrm{KAUH}$, the prevalence of severe stress in the medicine, surgery, $\mathrm{Ob} / \mathrm{Gyn}$, pediatrics, emergency, and elective clinics was $65.0 \%(n=13), 58.3 \%(n=7), 55.6 \%(n=5), 57.1 \%(n=4)$, $50.0 \%(n=1)$, and $70.0 \%(n=3)$, respectively (Figure 1).

\section{Discussion}

Our previous studies have documented the stress levels among Saudi medical students, but not the junior doctors. ${ }^{8,25}$ In view of our previous findings, this study is an extension

Table 2 Associations between stress prevalence and levels of stress in male and female interns

\begin{tabular}{|c|c|c|c|c|c|}
\hline Stress level & Sex & Stress (\%) & OR & $95 \% \mathrm{Cl}$ & $P$-value \\
\hline \multirow[t]{2}{*}{ Mild } & Male & $54 / 169(21.3)$ & 0.64 & $0.33-1.23$ & 0.178 \\
\hline & Female & $24 / 126(16.0)$ & 1 & & \\
\hline \multirow[t]{2}{*}{ Moderate } & Male & $41 / 169(16.1)$ & 1 & & \\
\hline & Female & $35 / 126(23.3)$ & 3.02 & I.59-5.72 & 0.0007 \\
\hline \multirow[t]{2}{*}{ Severe } & Male & $74 / 169(29.1)$ & 1 & & \\
\hline & Female & $67 / 126$ (44.7) & 3.21 & $|.83-5.6|$ & $<0.0001$ \\
\hline \multicolumn{6}{|l|}{ Hospital } \\
\hline \multirow[t]{2}{*}{ KKUH } & Male & II3/I 74 (64.9) & I & & \\
\hline & Female & $64 / 76(84.2)$ & 2.88 & $1.44-5.74$ & 0.003 \\
\hline \multirow[t]{2}{*}{$\mathrm{KAUH}$} & Male & $28 / 4 \mid(68.3)$ & 1 & & \\
\hline & Female & $35 / 40(87.5)$ & 3.25 & $1.03-10.21$ & 0.044 \\
\hline \multirow[t]{2}{*}{ KFHU } & Male & 28/39 (71.8) & 1 & & \\
\hline & Female & $27 / 34(79.4)$ & 1.52 & $0.5 I-4.48$ & 0.453 \\
\hline \multirow[t]{2}{*}{ Total } & Male & $169 / 254(66.5)$ & 1 & & \\
\hline & Female & $126 / 150(84.0)$ & 2.64 & $1.59-4.39$ & 0.0002 \\
\hline
\end{tabular}

Abbreviations: OR, odds ratio; $\mathrm{Cl}$, confidence interval; KKUH, King Khalid University Hospital; KAUH, King Abdulaziz University Hospital; KFHU, King Fahd Hospital of the University. 
Table 3 Associations between prevalence of stress among medical interns in different clinical cycles

\begin{tabular}{|c|c|c|c|c|c|}
\hline Hospital & Clinic & Stress (\%) & OR & $95 \% \mathrm{Cl}$ & $P$-value \\
\hline \multirow[t]{6}{*}{ KKUH } & Medicine & $46 / 6 I(75.5)$ & 2.04 & $0.62-6.69$ & 0.237 \\
\hline & Surgery & $38 / 51$ (74.5) & 1.95 & $0.58-6.53$ & 0.280 \\
\hline & Ob/Gyn & $34 / 51$ (66.7) & 1.33 & $0.40-4.36$ & 0.634 \\
\hline & Pediatrics & $34 / 49(69.4)$ & $1.5 \mathrm{I}$ & $0.45-5.01$ & 0.500 \\
\hline & Emergency & $9 / 15(60.0)$ & 1.00 & & \\
\hline & Elective & I6/23 (69.6) & 1.62 & $0.4 I-6.29$ & 0.487 \\
\hline \multirow[t]{6}{*}{ KAUH } & Medicine & $16 / 19(84.2)$ & 3.56 & $0.40-31.23$ & 0.253 \\
\hline & Surgery & $12 / 16(75.0)$ & 2.00 & $0.24-16.61$ & 0.521 \\
\hline & Ob/Gyn & II/I4 (78.6) & 2.44 & $0.27-22.01$ & 0.425 \\
\hline & Pediatrics & 14/I7 (82.4) & 3.11 & $0.35-27.54$ & 0.308 \\
\hline & Emergency & $3 / 5(60.0)$ & 1.00 & & \\
\hline & Elective & $7 / 10(70.0)$ & 1.56 & $0.16-14.65$ & 0.699 \\
\hline \multirow[t]{6}{*}{ KFHU } & Medicine & $20 / 24(83.3)$ & 5.00 & $0.53-46.72$ & 0.158 \\
\hline & Surgery & $12 / 16(75.0)$ & 3.00 & $0.31-28.84$ & $0.34 I$ \\
\hline & Ob/Gyn & $9 / 12(75.0)$ & 3.00 & $0.28-31.63$ & 0.361 \\
\hline & Pediatrics & $7 / 10$ (70.0) & 2.33 & $0.2 \mathrm{I}-25.24$ & 0.486 \\
\hline & Emergency & $2 / 4(50.0)$ & 1.00 & & \\
\hline & Elective & $5 / 7(7 \mid .4)$ & 2.50 & $0.19-32.19$ & 0.482 \\
\hline \multirow[t]{6}{*}{ All } & Medicine & $82 / 104$ (78.8) & 2.66 & $1.04-6.80$ & 0.041 \\
\hline & Surgery & $62 / 83(74.7)$ & 2.11 & $0.8 I-5.45$ & 0.124 \\
\hline & Ob/Gyn & $54 / 77(70.1)$ & 1.68 & $0.65-4.32$ & 0.285 \\
\hline & Pediatrics & $55 / 76(72.4)$ & 1.87 & $0.72-4.85$ & 0.199 \\
\hline & Emergency & $14 / 24(58.3)$ & 1.00 & & \\
\hline & Elective & $28 / 40(70.0)$ & 1.67 & $0.57-4.79$ & 0.343 \\
\hline
\end{tabular}

Abbreviations: OR, odds ratio; $\mathrm{Cl}$, confidence interval; KKUH, King Khalid University Hospital; Ob/Gyn, obstetrics and gynecology; KAUH, King Abdulaziz University Hospital; KFHU, King Fahd Hospital of the University.

of our earlier reports. ${ }^{8,25}$ Here, in this study, we assessed the prevalence of stress during internship training programs among Saudi medical colleges. To the best of our knowledge, this is the first study exploring the stress levels among the newly graduated interns of Saudi Arabian medical colleges. This study is important and has future impacts, as there is a paucity of research on stress levels during medical internships in other countries. Only a few reports have been published about stress and depression levels among interns; although the prevalence of depression among medical students and residence doctors has been reported elsewhere..$^{5,19,22}$ Earlier, we reported that the prevalence of stress among Saudi medical students is quite high (63\%), and that severe stress $(25 \%)$ is the most frequent level. ${ }^{25}$ The overall stress prevalence

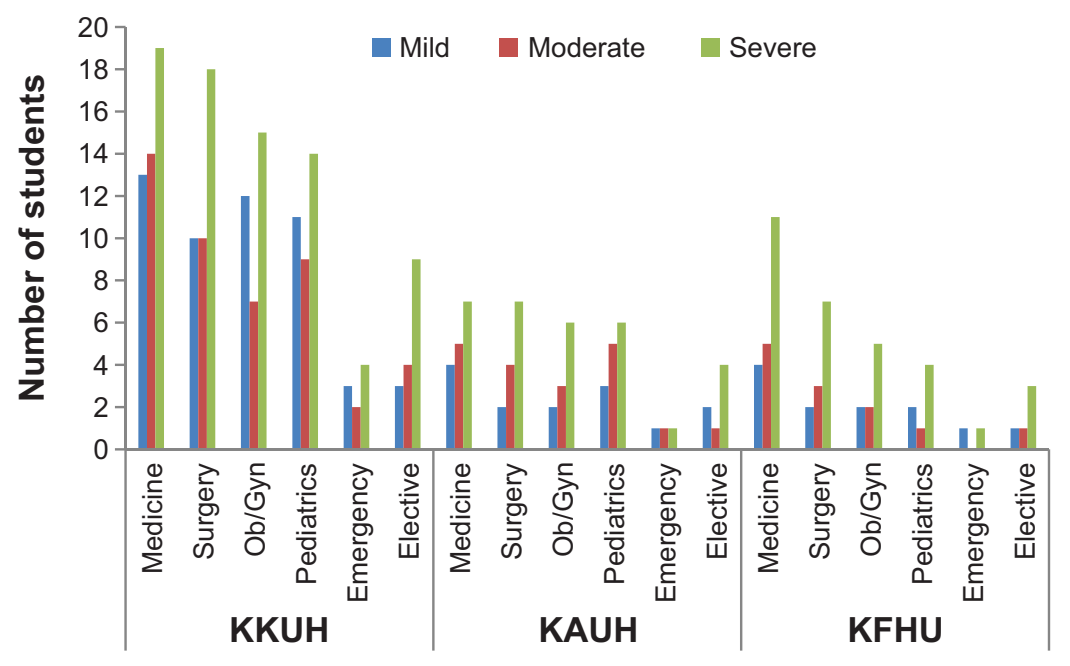

Figure I Stress levels among medical interns and clinical cycles in different medical colleges.

Abbreviations: Ob/Gyn, obstetrics and gynecology; KKUH, King Khalid University Hospital; KAUH, King Abdulaziz University Hospital; KFHU, King Fahd Hospital of the University. 
reported by medical interns in the present study is higher than what has been reported previously during medical graduation. The results indicated that only a small portion of the interns were affected with mild $(19.30 \%)$ or moderate $(18.81 \%)$ levels of stress, whereas a high proportion of interns (34.90\%) had severe stress levels. These results were consistent with those of a report stating that high depressive symptoms were found in Brazilian medical students during medical education and training. ${ }^{28}$ In another report, interns had the highest stress scores, both in total and across individual stress scale items, when compared with residents and graduate students. ${ }^{29}$ The female interns had a marginally higher prevalence of stress than their male counterparts ( $\mathrm{OR}=2.64$; $\mathrm{CI}=1.59-4.39$; $P=0.0002$ ). The results were similar to those of a previous local study that reported a higher prevalence of stress among female medical students $(\mathrm{OR}=2.3 ; P<0.0001){ }^{30}$ The findings were also consistent with international reports, in which female medical trainees reported more stress than male trainee doctors during their postgraduate training years. ${ }^{30,31}$ The sex variation in stress status in Saudi medical graduates and interns could be a reflection of the usual trend of a high prevalence of depression in females in the general population. ${ }^{32}$ The prevalence of stress in Saudi females may be attributed to multiple factors, which include social, cultural, and religious factors. The Saudi culture does not allow intermingling of the sexes. Hence, Saudi female students commonly maintain a proper distance from males or isolate themselves from "male related/involved" activities at their workplaces. ${ }^{33}$ Also, since most of the females are maintaining family life, they need to make an extra effort to maintain their seamless medical profession and generally they struggle to get appropriate postgraduate degrees in the medical profession. A lower percentage of female doctors achieve a specialist or consultant position than their male counterparts, despite having similar qualifications and years of experience. ${ }^{34} \mathrm{An}$ international study reported that female trainees from a medicine background experience more stress than males for their choice of medicine as a career versus home (family life). ${ }^{31,35}$ Therefore, female interns might be striving harder to reach their goals with much longer physical and mental hours spent coping with work and family needs. This might be a promoting factor for the higher prevalence of stress among female interns when compared to male interns.

Marital status did not have any effect on the stress scores among the Saudi interns in this study. This result is consistent with that of previous local studies, which showed no significant association between the marital status of medical students and stress prevalence. ${ }^{36,37}$ Also, an international study failed to observe any differences in depression and anxiety scores among the married and unmarried doctors. ${ }^{38}$ In contrast, married Saudi dental students perceived more stress than the unmarried students..$^{39,40}$ However, several studies from Western countries have indicated that marriage is a protective factor against depression. ${ }^{41,42}$ Marriage is a socially supported, stable, and enduring relationship that acts as a sort of insurance against psychological illness ${ }^{43}$ Hence, a published study reported that the supportive relationship had a protective effect against functional disability as a risk factor for developing depression in the future. ${ }^{44}$

We also evaluated stress in different training clinics in all three hospitals. This study is unique as, to our knowledge, there are no previous studies focused on the stress related to the clinic of internship. The findings of this study demonstrated that the levels of stress varied among different training clinics. The interns in the medical rotation reported the highest level of perceived stress, which was significantly higher than those among the interns from other clinics in all three hospitals. The second most stressful training clinics were surgery at $\mathrm{KKUH}$, pediatrics at KAUH, and surgery and $\mathrm{Ob} / \mathrm{Gyn}$ at KFHU. However, the prevalence of severe stress was highest in the surgery clinic followed by the medicine clinic in all three hospitals (Figure 1). The stress levels among the interns in different clinics may be due to the fierce competition lying ahead in the form of medical specialty and postgraduate entrance examinations. The different specialties chosen by interns for their careers are an important determinant of future planning of the workforce of health care services. ${ }^{45,46}$ Two recent local reports stated that the specialty most preferred by male students was surgery, followed by medicine, while the specialty most preferred by female students was surgery, followed by pediatrics. ${ }^{47,48}$ The factors that contribute to the choice of medical specialty include exposure during the internship year (whether there was exposure to the different subspecialties during internship) and the types of rotations. ${ }^{49} \mathrm{In}$ addition, careers in medicine have been known to be stressful. ${ }^{50}$ Medical internship training is a stressful course, characterized by frequent encounters with severely ill patients, diagnostic challenges, intellectual content, satisfaction in deepening the study of patients, ambulatory practice, the opportunity to be involved in the psychological and social aspects of medicine, and the desire to contribute to the community. ${ }^{51,52}$ On the other hand, students who choose surgical specialties justify their choice in terms of the opportunity to perform practical procedures and operations, as well as the associated prestige of surgery within the medical profession. ${ }^{53}$

Overall, reasonable levels of stress may not have a negative impact on successful internship training. However, excessive levels of stress might be harmful to a physician's life and clinical practice. ${ }^{54}$ The increased levels of stress 
indicate a decrease in the physician's psychological health, which could impair the students' behavior, diminish their learning, and affect the care of patients. ${ }^{55}$ Stebbing et $\mathrm{l}^{56}$ indicated that work-related stress can affect a doctor's health and result in poor morale, motivation, communication, and decision making, as well as poor relationships with colleagues. Hence, students under severe stress need help and subsequent interventions in terms of appropriate diagnosis, counseling, and even medications, to cope with their stress and depression levels. International efforts to decrease stress and improve job satisfaction among interns have been made, such as reducing working hours, increasing workplace flexibility, and providing career advice and educational resources. ${ }^{57,58}$

This cross-sectional study was based on a convenient sampling method and self-reported information provided by the participating interns. Therefore, there is some potential for possible reporting biases, which may have occurred because of the respondents' interpretation of the questions or desire to report their emotions in a certain way, or simply due to the inaccuracies of responses. However, the increased stress prevalence among the interns is an alarming sign. Another longitudinal study should be carried out with a cohort of interns to investigate the levels of stress and other associated factors including help from supervisors, team spirit, autonomy, job satisfaction, family relationships, transportation, working hours, and workplace flexibility.

\section{Conclusion}

This study showed a relative high prevalence of stress among new Saudi medical graduates during their internship. The findings suggest that there are high levels of perceived stress in the medical clinical rotation, followed by surgery during the period of internship. The findings also demonstrated that females perceived a higher level of stress than males. This study may be helpful for devising interventions to be implemented on the campuses to provide social and psychosocial support and counseling to reduce stress during the internship period. This study is also useful for encouraging the college faculty and staff to work in collaboration with the interns and develop appropriate support services during the internship period.

\section{Acknowledgments}

We are grateful to Dr Elizabeth Feeley and Dr Gominda Ponnamperuma for revising the whole manuscript for linguistic corrections.

This work was funded by the College of Medicine Research Center, Deanship of Scientific Research, King Saud University, Riyadh, Saudi Arabia.

\section{Disclosure}

The authors report no conflicts of interest in this work.

\section{References}

1. Levine RB, Haidet P, Kern DE, et al. Personal growth during internship: a qualitative analysis of interns' responses to key questions. J Gen Intern Med. 2006;21(6):564-569.

2. Lam T, Ching L. An exploratory study of an internship program: The case of Hong Kong students. Int J Hosp Manag. 2007;26(2):336-351.

3. Ackerman A, Graham M, Schmidt H, Stern DT, Miller SZ. Critical events in the lives of interns. J Gen Intern Med. 2009;24(1):27-32.

4. Levey RE. Sources of stress for residents and recommendations for programs to assist them. Acad Med. 2001;76(2):142-150.

5. Wilson I, Cowin LS, Johnson M, Young H. Professional identity in medical students: pedagogical challenges to medical education. Teach Learn Med. 2013;25(4):369-373.

6. Sun GR, Saloojee H, van-Rensburg MJ, Manning D. Stress during internship at three Johannesburg hospitals. S Afr Med J. 2008;98(1): 33-35.

7. Linn LS, Yager J, Cope DW, Leake B. Factors associated with life satisfaction among practicing internists. Med Care. 1986;24(9): 830-837.

8. Abdulghani HM. Stress and depression among medical students: A cross sectional study at a medical college in Saudi Arabia. Pak J Med Sci. 2008;24(1):12-17.

9. Anderson CA, Arnoult LH. An examination of perceived control, humor, irrational beliefs, and positive stress as moderators of the relation between negative stress and health. Basic Appl Soc Psych. 1989; 10(2):101-117.

10. Vincent T. Stress management: Healthy vs unhealthy. Michigan Bar Journal. 2012:54-55.

11. Bangal VB, Shinde KK, Gavhane SP. Review of reasons and remedial measures for burnout during residency programme. International Journal of Biomedical and Advance Research. 2012;3(8): 613-617.

12. Hwang JW, Hahm BJ, Kwon ST, Kim KH, Lee JR. Impact of lifetime subthreshold depression and major depression before internship on psychopathology and quality of life in Korean interns: 6 month follow-up study. Aust N Z J Psychiatry. 2008;42(4):301-308.

13. Brosschot JF, Gerin W, Thayer JF. The perseverative cognition hypothesis: a review of worry, prolonged stress-related physiological activation, and health. J Psychosom Res. 2006;60(2):113-124.

14. LeBlanc VR. The effects of acute stress on performance: implications for health professions education. Acad Med. 2009;84(10): S25-S33.

15. Kato T. Coping with interpersonal stress and psychological distress at work: comparison of hospital nursing staff and salespeople. Psychol Res Behav Manag. 2014;7:31-36.

16. Wilhelm K. The student and junior doctor in distress. Medical Journal of Australia. 2002;177:S5-S8.

17. Bellini LM, Baime M, Shea JA. Variation of mood and empathy during internship. JAMA. 2002;287(23):3143-3146.

18. Deshpande JD, Phalke DB, Kalakoti P, Qutub D, Agrawal V. Stress levels and depression amongst interns and resident doctors working in a tertiary care teaching hospital in rural area. International Journal of Health and Rehabilitation Sciences. 2013;2(1):44-49.

19. Røvik JO, Tyssen R, Hem E, et al. Job stress in young physicians with an emphasis on the work-home interface: a nine-year, nationwide and longitudinal study of its course and predictors. Ind Health. 2007; 45(5):662-671.

20. Tyssen R, Vaglum P, Grønvold NT, Ekeberg Ø. The relative importance of individual and organizational factors for the prevention of job stress during internship: a nationwide and prospective study. Med Teach. 2005;27(8):726-731.

21. Liu CC, Wissow LS. Residents who stay late at hospital and how they perform the following day. Med Educ. 2008;42(1):74-81. 
22. Bruce $\mathrm{C}$, Thomas PS, Yates DH. Health and stress in Australian interns. Intern Med J. 2003;33(8):392-395.

23. Coombes ID, Stowasser DA, Coombes JA, Mitchell C. Why do interns make prescribing errors? A qualitative study. Med J Aust. 2008;188(2): 89-94.

24. Alzahem AM, Vander-Molen HT, De-Boer BJ. Effect of year of study on stress levels in male undergraduate dental students. Adv Med Educ Pract. 2013;8(4):217-222.

25. Abdulghani HM, AlKanhal AA, Mahmoud ES, et al. Stress and its effects on medical students: a cross-sectional study at a college of medicine in Saudi Arabia. J Health Popul Nutr. 2011;29(5):516-522.

26. Tyssen R, Vaglum P, Gronvold NT, Ekeberg O. The impact of job stress and working conditions on mental health problems among junior house officers. A nationwide Norwegian prospective cohort study. Med Educ. 2000;34(5):374-384.

27. Kessler RC, Andrews G, Colpe LJ, et al. Short screening scales to monitor population prevalences and trends in non-specific psychological distress. Psychol Med. 2002;32(6):959-976.

28. Baldassin S, Alves TC, de-Andrade AG, Noqueira Martins LA. The characteristics of depressive symptoms in medical students during medical education and training: a cross-sectional study. BMC Med Educ. 2008;8:60

29. Stucky ER, Dresselhaus TR, Dollarhide A, et al. Intern to attending: assessing stress among physicians. Acad Med. 2009;84(2):251-257.

30. Gramstad TO, Gjestad R, Haver B. Personality traits predict job stress, depression and anxiety among junior physicians. BMC Med Educ. 2013; 13:150.

31. Yogev S, Harris S. Women physicians during residency years: workload, work satisfaction and self-concept. Soc Sci Med. 1983;17(12):837-841.

32. Al-Dabal BK, Koura MR, Rasheed P, Al-Sowielem L, Makki SM. A comparative study of perceived stress among female medical and nonmedical university students in Dammam, Saudi Arabia. Sultan Qaboos Univ Med J. 2010;10(2):231-240.

33. Hamdan A. Women and education in Saudi Arabia: Challenges and achievements. International Education Journal. 2005;6(1):42-64.

34. Al-Tamimi DM. Saudi women in academic medicine. Are they succeeding? Saudi Med J. 2004;25(11):1564-1567.

35. Robinson GE. Stresses on women physicians: consequences and coping techniques. Depress Anxiety. 2003;17(3):180-189.

36. Sani M, Mahfouz MS, Bani I, et al. Prevalence of stress among medical students in Jizan University, Kingdom of Saudi Arabia. Gulf Medical Journal. 2012;1(1):19-25.

37. El-Masry R, Ghreiz SM, Helal RM, Audeh AM, Shams T. Perceived stress and burnout among medical students during the clinical period of their education. Ibnosina Journal of Medicine and Biomedical Sciences. 2013;5(4):179-188.

38. Erdur B, Ergin A, Turkcuer I, Parlak I, Ergin N, Boz B. A study of depression and anxiety among doctors working in emergency units in Denizli, Turkey. Emerg Med J. 2006;23(10):759-763.

39. Pani SC, Al-Askar AM, Al-Mohrij SI, Al Ohali TA. Evaluation of stress in final-year Saudi dental students using salivary cortisol as a biomarker. J Dent Educ. 2011;75(3):377-384.

40. Al-Sowygh ZH. Academic distress, perceived stress and coping strategies among dental students in Saudi Arabia. Saudi Dent J. 2013; 25(3):97-105.
41. Lloyd S, Streiner D, Shannon S. Burnout, depression, life and job satisfaction among Canadian emergency physicians. J Emerg Med. 1994;12(4):559-565.

42. Taylor DM, Pallant JF, Crook HD, Cameron PA. The psychological health of emergency physicians in Australasia. Emerg Med Australas. 2004;16(1):21-27.

43. Nambi S. Marriage, mental health and the Indian legislation. Indian $J$ Psychiatry. 2005;47(1):3-14.

44. Ozbay F, Fitterling H, Charney D, Southwick S. Social support and resilience to stress across the life span: a neurobiologic framework. Curr Psychiatry Rep. 2008;10(4):304-310.

45. Abendroth J, Schnell U, Lichte T, Oemler M, Klement A. Motives of former interns in general practice for speciality-choice - results of a cross-sectional study among graduates 2007 to 2012. GMS Z Med Ausbild. 2014;31(1):1-12.

46. Eze BI, Okoye OI, Maduka-Okafor FC, Aquwa EN. Factors influencing choice of medical specialty of preresidency medical graduates in southeastern Nigeria. J Grad Med Educ. 2011;3(3): 367-371.

47. Mehmood SI, Kumar A, Al-Binali A, Borleffs JC. Specialty preferences: trends and perceptions among Saudi undergraduate medical students. Med Teach. 2012;34 Suppl 1:S51-S60.

48. Abdulghani HM, Al-Shaikh G, Alhujayri AK, et al. What determines the selection of undergraduate medical students to the specialty of their future careers? Med Teach. 2013;35 Suppl 1:S25-S30.

49. Al-Ansari SS, Khafagy MA. Factors affecting the choice of health specialty by medical graduates. J Family Community Med. 2006; 13(3):119-123

50. Prins JT, Gazendam-Donofrio SM, Tubben BJ, van der Heijden FM, van de Wiel HB, Hoekstra-Weebers JE. Burnout in medical residents: a review. Med Educ. 2007;41(8):788-800.

51. Batenburg V, Smal JA, Lodder A, de-Melker RA. Are professional attitudes related to gender and medical specialty? Med Educ. 1999; 33(7):489-492.

52. Vaglum P, Wiers-Jenssen J, Ekeberg O. Motivation for medical school: the relationship to gender and specialty preferences in a nationwide sample. Med Educ. 1999;33(4):236-242.

53. Gelfand DV, Podnos YD, Wilson SE, Cooke J, Williams RA. Choosing general surgery: insights into career choices of current medical students. Arch Surg. 2002;137(8):941-947; discussion 945-947.

54. Waterman AD, Garbutt J, Hazel E, et al. The emotional impact of medical errors on practicing physicians in the United States and Canada. Jt Comm J Qual Patient Saf. 2007;33(8):467-476.

55. Bastos JCF, Mohallem AGC, Farah OGD. [Anxiety and depression in nursing students during oncology internship]. Einstein. 2008;6(1):7-12. Portuguese.

56. Stebbing J, Sundhiya M, Simon P, et al. A questionnaire survey of stress and bullying in doctors undertaking research. Postgrad Med J. 2004; 80(940):3-96.

57. Lewis A. Safe working hours-doctors in training a best practice issue. Aust Health Rev. 2002;25(6):100-108.

58. Mogi K, Inoue S, Sato M, Taga N, Hirabayashi Y, Seo N. [Study on the working conditions of rotating residents in the department of anesthesia under the new residency programs]. Masui. 2008;57(1):92-94. Japanese.
Neuropsychiatric Disease and Treatment

\section{Publish your work in this journal}

Neuropsychiatric Disease and Treatment is an international, peerreviewed journal of clinical therapeutics and pharmacology focusing on concise rapid reporting of clinical or pre-clinical studies on a range of neuropsychiatric and neurological disorders. This journal is indexed on PubMed Central, the 'PsycINFO' database and CAS,

\section{Dovepress}

and is the official journal of The International Neuropsychiatric Association (INA). The manuscript management system is completely online and includes a very quick and fair peer-review system, which is all easy to use. Visit http://www.dovepress.com/testimonials.php to read real quotes from published authors. 